\title{
[Regular Paper] \\ Interaction of Hindered Amine Light Stabilizers and Ultraviolet Absorbers
}

\author{
Hiroyuki TakenaKa, Shigeo MizoKawa, and Yasukazu OHKatsu* \\ Dept. of Applied Chemistry, Faculty of Engineering, Kogakuin University, 1-24-2 Nishishinjuku, Shinjuku-ku, Tokyo 163-8677, JAPAN
}

(Received December 9, 2005)

\begin{abstract}
The reason is discussed, why ultraviolet absorbers (UVA) having phenolic moiety show the synergism with HALS apparently, on the contrarily to phenolic antioxidants. A HALS nitrosonium is a substrate causing the useless oxidation of a phenol, and is formed from HALS more easily in the presence of a phenol. However, 2-hydroxybenzophenone (2-HBP) did not accelerate the formation of the nitrosonium so fast as 3,5-di-t-butyl4-hydroxytoluene (BHT). A HALS nitrosonium, even if formed, did not oxidize 2-HBP so much as BHT. That is, 2-HBP can continue to work longer and more efficiently in the presence of HALS. This fact suggests a weak antagonism of 2-HBP and a strong antagonism of BHT with HALS. On the other hand, quinones, derived from 2-HBP and BHT as result of peroxy radical-catching, were reduced to the corresponding hydroquinones by the action of HALS derivatives, such as HALS hydroxylamine. This reaction occurs strikingly faster and more easily for 2-HBP than for BHT. This fact shows a strong synergism of 2-HBP and a weak synergism of BHT with HALS. The above-mentioned results well explain the apparent synergism of UVA (2-HBP) with HALS, contrarily to the apparent antagonism of BHT with HALS.
\end{abstract}

\section{Keywords}

HALS, UVA, Antagonism, Synergism, Photo-oxidation, Quinone

\section{Introduction}

Hindered amine light stabilizers (HALS) are important additives for the stabilization and long service-life of polymeric materials. They have many functions to control the degradation of polymeric materials, and their antioxidant action mechanisms have been studied intensively. In particular, a hydroperoxide decomposition by HALS is an important step forming active species of HALS for stabilization. In a previous paper, the authors reported a new fact that a hydroperoxide decomposition by HALS NH proceeds through homolytical chain reactions and is accelerated by the presence of 3,5-di-t-butyl-4-hydroxytoluene (BHT), one of phenolic antioxidants ${ }^{1}$. In addition, they also reported that a nitrosonium salt of HALS is produced during a hydroperoxide decomposition by HALS, and its formation is accelerated by a phenol. The nitrosonium works as bad species having a considerably high activity of a homolytical hydroperoxide decomposition ${ }^{2}$, and also oxidizes and consumes a phenol uselessly. Thus, an entirely new antagonism between HALS and phenols was proposed $^{2)}$.

The HALS were developed as light stabilizers, but the decisive explanation, including a direct action on

\footnotetext{
* To whom correspondence should be addressed.

* E-mail: ohkatsu@cc.kogakuin.ac.jp
}

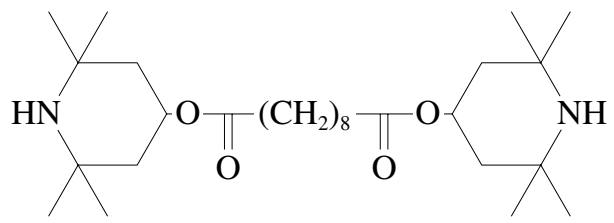

HALS NH (as one of HALS)

photo-antioxidant activities of HALS, has not been done except for the author's proposal ${ }^{3)}$. A phenol catches peroxy radicals to be a quinone. The quinone absorbs light well to be a photo-excited quinone, which goes into photolysis and accelerates the autoxidation degradation. However, HALS prevent such degradation by reducing the excited quinone to a phenol (see Scheme 1). As a result, HALS seem to work as light stabilizer. This is only one photo-stabilizing mechanism explaining a synergism of HALS and phenols ${ }^{3)}$.

The HALS and ultraviolet absorbers (UVA) show synergism. Pickett et $a l .{ }^{4)}$ described that HALS and benzotriazole type UVA do not interact with each other directly, but they apparently work synergistically, because they independently take part in different light stabilization processes: that is, HALS protect UVA from losing the functions by catching peroxy radicals. However, Decker et al. ${ }^{5)}$ reported that HALS tend to be consumed slowly in the presence of benzotriazole type 


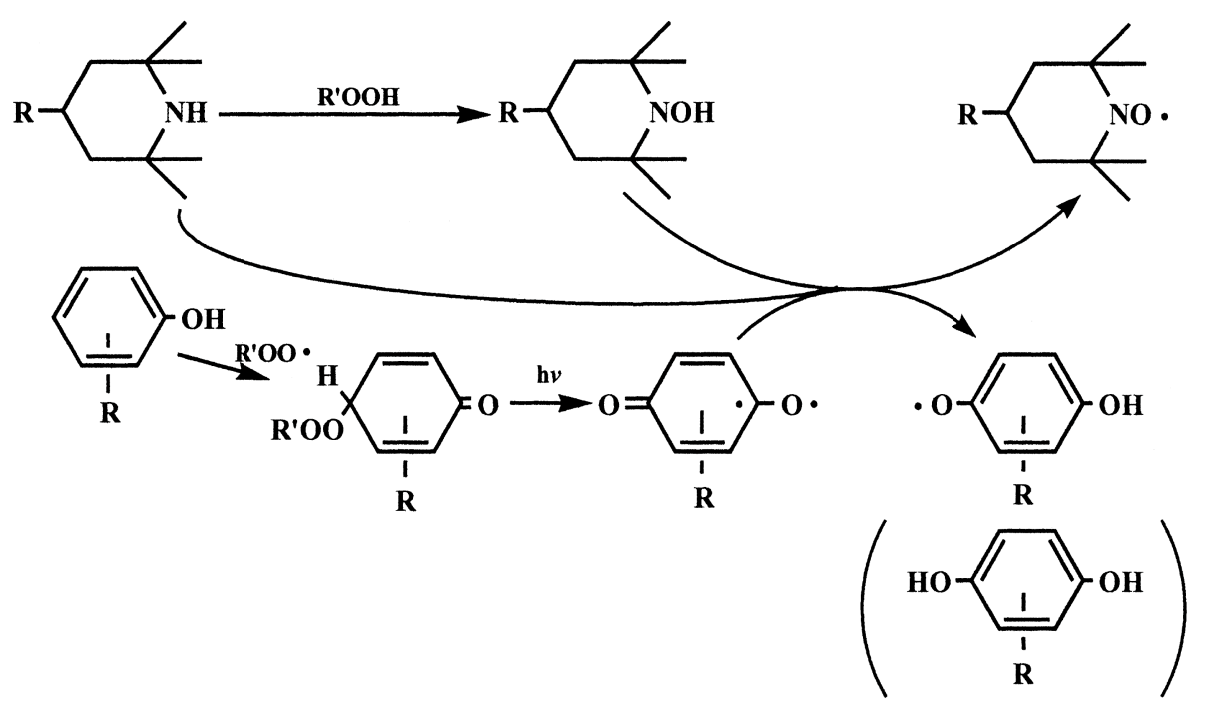

Scheme 1 Synergism between HALS and Phenolic Antioxidant for Polymer Stabilization

UVA, but keep UVA in plastics much longer, although HALS do not affect any photolysis of UVA. However, these mechanisms do not seem to explain the synergism perfectly. On the other hand, the authors reported a good relationship between the inhibition of photooxidation by UVA and the initial rate of homolytic decomposition of a hydroperoxide by HALS in the presence of UVA, and concluded no or little antagonism of UVA with HALS $^{6}$. In this study, we confirm it experimentally and propose a new synergism of HALS and UVA by comparing the action of UVA (2-hydroxybenzophenone) with that of phenol (BHT) with respect to both antagonism and synergism with HALS.

\section{Experimental}

\section{1. Reagents}

Bis(2,2,6,6-tetramethyl-4-piperidinyl)sebacate (designated HALS NH) (ADK stab LA-77) was purified by a conventional method. Cumene hydroperoxide (designated CHP) (Nacalai Tesque Inc.) was used as a hydroperoxide. Chlorobenzene (GODO Solvents Co.) was purified by a general method. 2-Hydroxybenzophenone (designated 2-HBP) (Tokyo Chemical Industry Co., Ltd.) and 3,5-di-t-butyl-4-hydroxytoluene (designated BHT) (Tokyo Chemical Industry Co., Ltd.) was purified by conventional methods.

\section{1. 1. Syntheses}

(a) Bis(1-oxy-2,2,6,6-tetramethyl-4-piperidinyl)sebacate (designated HALS NO)

The HALS NH of $13 \mathrm{~g}$ was dissolved in $200 \mathrm{ml}$ of methanol, and $7 \mathrm{ml}$ of acetonitrile was added. Then, $3.6 \mathrm{~g}$ of sodium hydrogen carbonate, $0.5 \mathrm{~g}$ of sodium tungstate, and $20 \mathrm{ml}$ of $35 \%$ aqueous hydrogen peroxide solution were added. The mixture was stirred for 4 days at room temperature. After the addition of
$200 \mathrm{~m} l$ of saturated brine, the solution was extracted with diethyl ether. The solvent was distilled off in vacuo, and a product was purified by means of a column chromatography (stationary phase: silica gel, mobile phase: chloroform : acetone $=10: 1$ ) and by the recrystallization from hexane. A pale orange crystal was obtained.

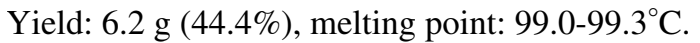

FT-IR $(\mathrm{KBr})$ : over $3321 \mathrm{~cm}^{-1}(>\mathrm{NH})$ disappeared, $1716 \mathrm{~cm}^{-1}$ (ester), 1180 and $988 \mathrm{~cm}^{-1}$ ( $>$ NO) appeared.

(b) B i s ( 1 - h y d r o x y -2,2,6,6-te tra m e t h y l-4piperidinyl)sebacate (designated HALS NOH)

The HALS NO $1.0 \mathrm{~g}(2.0 \mathrm{mmol})$ was dissolved in slight benzene. Water $(20 \mathrm{ml})$ containing $1.5 \mathrm{~g}$ of ammonium chloride was added. Then $1.0 \mathrm{~g}$ of zinc powder was added, and the mixture was stirred under nitrogen atmosphere at room temperature until the organic phase became colorless. The benzene phase was separated after zinc was filtered off, washed with saturated brine, and dried over anhydrous sodium sulfate in a glove box purged with nitrogen. Then, the solvent was removed in vacuo. The residue was recrystallized from carbon tetrachloride under nitrogen atmosphere to give white crystal.

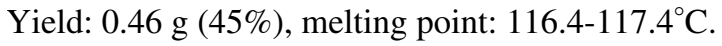

FT-IR (KBr): $3462 \mathrm{~cm}^{-1}$ (-OH), $1712 \mathrm{~cm}^{-1}$ (ester), $988 \mathrm{~cm}^{-1}$ (NO) disappeared.

${ }^{1} \mathrm{H}-\mathrm{NMR}\left(\mathrm{CDCl}_{3}\right.$, TMS $): 7.3 \mathrm{ppm}(2 \mathrm{H}, \mathrm{OH}), 5.1 \mathrm{ppm}$ (2H, COOCH), 2.4-1.2 ppm (48H, $\left.\mathrm{CH}_{3}, \mathrm{CH}_{2}\right)$.

(c) 4-Acetoxy-2,2,6,6-tetramethylpiperidine (designated acetate HALS NH)

4-Hydroxy-2,2,6,6-tetramethylpiperidine $9.44 \mathrm{~g}$ (0.06 $\mathrm{mol})$ was dissolved in $20.6 \mathrm{ml}(0.36 \mathrm{~mol})$ of acetic acid, and $1 \mathrm{ml}$ of concentrated sulfuric acid was added. The mixture was stirred for $4 \mathrm{~h}$ at $100^{\circ} \mathrm{C}$. After the reaction, the solution was poured into an ice water and made 
basic a little with sodium hydroxide. The solution was extracted with dichloromethane. The solvent was removed under a reduced pressure, and pale yellow oil was obtained as product.

Yield: $3.67 \mathrm{~g}(30 \%)$. FT-IR (NaCl): $3327 \mathrm{~cm}^{-1}(\mathrm{NH}), 3400 \mathrm{~cm}^{-1}$ (-OH) disappeared, $1732 \mathrm{~cm}^{-1}$ (ester).

${ }^{1} \mathrm{H}-\mathrm{NMR}\left(\mathrm{CDCl}_{3}\right.$, TMS): $0.94 \mathrm{ppm}(1 \mathrm{H}, \mathrm{NH}), 1.5 \mathrm{ppm}$ $(1 \mathrm{H}, \mathrm{OH})$ disappeared, $2.0 \mathrm{ppm}(3 \mathrm{H}$, acetyl) appeared.

(d) 4-Hydroxy-1-oxy-2,2,6,6-tetramethylpiperidine

4-Hydroxy-2,2,6,6-tetramethylpiperidine $6.59 \mathrm{~g}$ $(0.04 \mathrm{~mol})$ was dissolved in $100 \mathrm{~m} l$ of methanol, and $15 \mathrm{ml}$ of acetonitrile was added. Then, $5.01 \mathrm{~g}$ $(0.05 \mathrm{~mol})$ of sodium hydrogen carbonate, $0.33 \mathrm{~g}$ $(0.001 \mathrm{~mol})$ of sodium tungstate, and $15 \mathrm{ml}$ of $35 \%$ hydrogen peroxide were added. The mixture was stirred for 4 days at room temperature. After the addition of $200 \mathrm{~m} l$ of saturated brine, the solution was extracted with diethyl ether. The solvent was distilled off in vacuo, and a product was purified by means of a column chromatography (stationary phase: silica gel, mobile phase: chloroform : acetone $=10: 1$ ) and recrystallized from hexane. A yellow crystal was obtained. Yield: $7.01 \mathrm{~g}(97 \%)$, melting point: $66.7-67.4^{\circ} \mathrm{C}$. FT-IR(KBr): over $3321 \mathrm{~cm}^{-1}(\mathrm{NH})$ disappeared, 1172.6, $991.3 \mathrm{~cm}^{-1}(\mathrm{NO})$.

(e) 4-Acetoxy-1-oxy-2,2,6,6-tetramethylpiperidine (designated acetate HALS NO)

4-Hydroxy-1-oxy-2,2,6,6-tetramethylpiperidine $3.5 \mathrm{~g}$ $(0.02 \mathrm{~mol})$ was dissolved in $40 \mathrm{ml}$ of benzene, and $2.05 \mathrm{~g}(0.02 \mathrm{~mol})$ of trifluoroacetic acid was added. Acetyl chloride $2.39 \mathrm{~g}(0.03 \mathrm{~mol})$ in $10 \mathrm{ml}$ of benzene was added dropwisely. The mixture was stirred for $24 \mathrm{~h}$ at room temperature, and the reaction solution was filtered. The solvent was distilled off in vacuo, and a product was purified by a column chromatography (stationary phase: silica gel, mobile phase: chloroform : acetone $=10: 1$ ) and recrystallized from hexane. A red crystal was obtained.

Yield: $3.45 \mathrm{~g}$ (79\%), melting point: $53.1-54.1^{\circ} \mathrm{C}$.

FT-IR (KBr): $3415.7 \mathrm{~cm}^{-1}(-\mathrm{OH})$ disappeared, $1741.6 \mathrm{~cm}^{-1}$ (ester).

(f) 4-Acetoxy-1-oxy-2,2,6,6-tetramethylpiperidinium nitrate/nitrite (designated acetate $\mathrm{HALS} \mathrm{N}^{+}=\mathrm{O}$ $\mathrm{NO}_{2}{ }^{-} / \mathrm{NO}_{3}{ }^{-}$)

The compound was synthesized by a method of $\mathrm{G}$. Kaupp et al. ${ }^{7}$. Nitrogen dioxide (ca. $7.2 l$ at $\left.0^{\circ} \mathrm{C}\right)$ was passed through a solution of 4-acetoxy-1-oxy-2,2,6,6tetramethylpiperidine $(0.5 \mathrm{~g})$ in a solvent at $-10^{\circ} \mathrm{C}$ for $2 \mathrm{~h}$. Then, the mixture was stirred for $2 \mathrm{~h}$ and remained nitrogen dioxide was removed by warming up to $50^{\circ} \mathrm{C}$. High viscous water-soluble crimson oil was obtained.

Yield $0.78 \mathrm{~g}(98 \%)$.

FT-IR ( NaCl): 2940, 1620, 1350, 1240, 1160 , $1100 \mathrm{~cm}^{-1}$ (nitrosonium salt ${ }^{8)}$ ), $1736 \mathrm{~cm}^{-1}$ (ester), and
$988 \mathrm{~cm}^{-1}$ (nitroxide) disappeared.

(g) 2,5-Dihydroxybenzophenone

Methane sulfonic acid $(25 \mathrm{~g})$ and $6.65 \mathrm{~g}(0.05 \mathrm{~mol})$ of aluminium oxide are added to $6.1 \mathrm{~g}(0.05 \mathrm{~mol})$ of benzoic acid and $5.51 \mathrm{~g}(0.05 \mathrm{~mol})$ of 1,4-benzenediol, and the mixture was stirred for $1 \mathrm{~h}$ at $140^{\circ} \mathrm{C}$. The reaction solution was cooled, and dil. $\mathrm{HCl}$ was added. The resulting solution was extracted with diethyl ether, and the organic phase was washed with saturated $\mathrm{NaHCO}_{3} \mathrm{aq}$, water, and saturated brine, and dried over anhydrous sodium sulfate. The solvent was distilled off in vacuo, and a product (yellow crystal) was purified by means of a column chromatography (stationary phase: silica gel, mobile phase: dichloromethane : ethyl acetate $=9: 1$ ) and recrystalized from carbon tetrachloride.

Yield: $1.02 \mathrm{~g}(9.6 \%)$, melting point: $121.8-122.4^{\circ} \mathrm{C}$.

FT-IR (KBr): $3298 \mathrm{~cm}^{-1}(-\mathrm{OH}), 1714.6 \mathrm{~cm}^{-1}(\mathrm{C}=\mathrm{O})$, $875.6 \mathrm{~cm}^{-1}\left(\mathrm{C}_{6} \mathrm{H}_{6}\right)$.

${ }^{1} \mathrm{H}-\mathrm{NMR}\left(\mathrm{CDCl}_{3}, \mathrm{TMS}\right): 11.6 \mathrm{ppm}(1 \mathrm{H}, 1-\mathrm{OH})$, 8.0-6.9 ppm (4H, $\left.\mathrm{C}_{6} \mathrm{H}_{4}\right), 5.0 \mathrm{ppm}(1 \mathrm{H}, 4-\mathrm{OH})$.

(h) 2-Benzoyl-p-quinone

2,5-Dihydroxybenzophenone ( $0.5 \mathrm{~g})$ was dissolved in $40 \mathrm{~m} l$ of diethyl ether. Silver oxide (I) $(5 \mathrm{~g})$ and $5 \mathrm{~g}$ of anhydrous sodium sulfate were added. The mixture was stirred for $3 \mathrm{~h}$ at room temperature in dark. Reaction solution was filtered, the filtrate was distilled off in vacuo, and a dark brown crystal was obtained as product.

Yield: $0.43 \mathrm{~g}(86 \%)$, melting point: $79.8-80.3^{\circ} \mathrm{C}$. FT-IR (KBr): $3298 \mathrm{~cm}^{-1}(-\mathrm{OH})$ disappeared, $1651 \mathrm{~cm}^{-1}$ $(\mathrm{C}=\mathrm{O}), 1596.9 \mathrm{~cm}^{-1}(\mathrm{C}=\mathrm{C})$.

\section{1. 2. Others}

Styrene was used after distillation just before use. An initiator, azo-bis-isobutyronitrile (AIBN), was purified by recrystallization from methanol.

\section{2. Procedure}

\section{2. 1. Decomposition Reaction of Hydroperoxide}

A HALS derivative, CHP, and a phenol were dissolved in chlorobenzene (the total volume: $100 \mathrm{ml}$ ). The solution was heated with stirring at $120^{\circ} \mathrm{C}$ under nitrogen atmosphere. A sample was taken at every $4 \mathrm{~h}$ and the remaining hydroperoxide was determined by iodometry or gas chromatography (GC), while reaction products were analyzed by $\mathrm{GC}$ and were identified by GC-MS. The reaction was repeated a few times to confirm the reproducibility. All graphs shown in this study show the most reliable one in terms of reproducibility.

\section{2. 2. Iodometry}

A solution of $10 \%$ acetic acid in 2-propanol was purged with carbon dioxide for two minutes to remove dissolved oxygen. To $5 \mathrm{~m} l$ of this solution was added $0.5 \mathrm{ml}$ of an aqueous saturated potassium iodide solution and $1 \mathrm{~m} l$ of a sample. The mixture was heated and stirred under carbon dioxide atmosphere at $95^{\circ} \mathrm{C}$ 


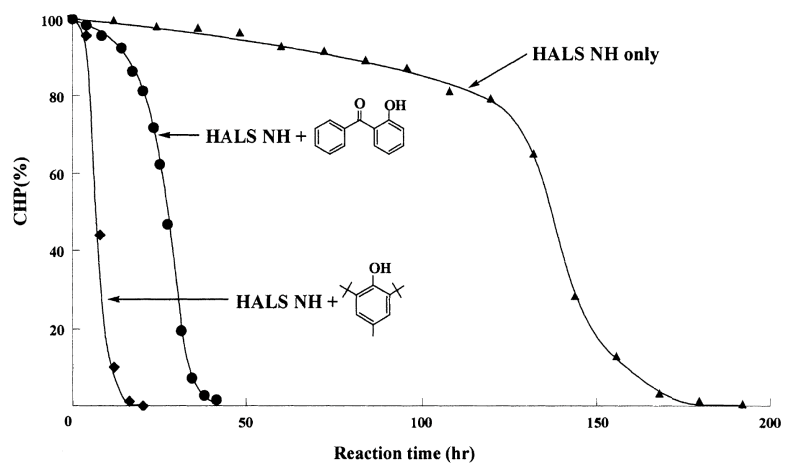

In chlorobenzene under $\mathrm{N}_{2}$ at $120^{\circ} \mathrm{C}$, [HALS NH] $=$ [phenol] $=$ $10^{-3} \mathrm{~mol} / l,[\mathrm{CHP}]=10^{-2} \mathrm{~mol} / l$.

Fig. 1 Effect of Phenolic Compound on Decomposition of CHP by HALS

for three minutes. The hydroperoxide content was determined by the titration with $1 / 1000 \mathrm{~N}$ standard sodium thiosulfate solution.

\section{2. 3. Instrumental Analysis}

The GC-17A or GC-14B made by Shimadzu Corp. was used as GC with a flame ionization detector (FID). And the GC-MS QP5050A made by Shimadzu Corp. was used as well. The 400-1HT (Quadrex Corp.) was used as column in both systems.

\section{2. 4. Measurement of Photo-antioxidant Activities}

Photo-oxidation of styrene was carried out in chlorobenzene under irradiation of UV light (high-pressure mercury-vapor lamp) above $290 \mathrm{~nm}$ : a high-pressure mercury-vapor lamp $(500 \mathrm{~W})$, manufactured by Ushio Inc., was used as light source. The oxidation was pursued by recording the consumed amount of oxygen by a pressure transducer.

\section{2. 5. Reaction of Quinone and HALS}

The HALS NOH or HALS NO and a quinone or hydroquinone were dissolved in carbon tetrachloride, and allowed to react under nitrogen atmosphere and diffused light at $50^{\circ} \mathrm{C}$. A hydroquinone generated or consumed in reactions was measured using a UV-spectrometer.

\section{Results and Discussion}

\section{1. Influence of UVA on Decomposition of Hydroperoxide by HALS NH}

The CHP decomposition by HALS NH was studied in the presence or absence of a phenol. Figure 1 shows the result. The decomposition curve consists of two stages of an early period showing slow decomposition and a late period, fast decomposition. The slow decomposition period is called an induction period, in which an active species is formed for the following fast decomposition showing maximum velocity. The induction period was about $120 \mathrm{~h}$ in the presence of only
HALS, but the coexistence of BHT or 2-HBP shortened the induction period and accelerated the homolytical decomposition of the hydroperoxide (see Fig. 1). However, 2-HBP exhibited a longer induction period than BHT. Thus, the benzophenone is found more difficult to produce an active species of hydroperoxide decomposition in comparison with BHT. In the case of BHT, it gives a proton to HALS more easily, and the resulting salt forms active species, namely HALS nitrosonium $^{2)}$. It has not been confirmed yet, however, whether a HALS nitrosonium is an active species in the case of UVA or not.

\section{2. HALS Derivatives Formed in Induction Period}

The decomposition reaction was carried out in the same manner as described in Paragraph 3. 1. using acetate HALS NH detectable in GC-MS. The reaction solution was analyzed by GC-MS at the middle time of the fast CHP decomposition, namely after $20 \mathrm{~h}$ of the reaction.

The gas chromatogram is shown in Fig. 2. Products A and B are identified from the MS spectra as reported in a previous paper as follows ${ }^{2)}$.
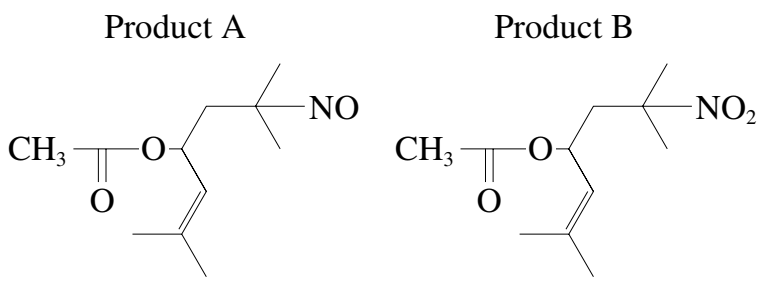

These products well means the presence of HALS nitrosonium during decomposition reaction ${ }^{2}$. Thus, an active species for hydroperoxide decomposition is HALS nitrosonium, also in the case of UVA. When UVA and BHT are compared with respect to the nitrosonium formation, UVA do not seem easier to produce the nitrosonium than BHT, because UVA hardly give proton to HALS due to intramolecular hydrogen bond. This explanation coincides well with the argument in Paragraph 3. 1.

\section{3. Oxidation of 2-HBP by HALS Nitrosonium}

A HALS nitrosonium is a strong oxidants, and oxidizes BHT to form the oxidized derivatives such as the $p$-benzoquinone, resulting in useless consumption of $\mathrm{BHT}^{2)}$. In this study, it was also investigated whether a HALS nitrosonium oxidizes UVA (Fig. 3).

On the basis of mass spectra, the reaction product $\mathrm{C}$ is identified as 2-benzoyl-p-quinone, and the main reaction products $\mathrm{D}$ are a mixture of nitro compounds formed by the attack of a counter nitrite anion of HALS nitrosonium.

Judging from the gas chromatogram shown in Fig. 3, the reaction product $\mathrm{C}$ is formed by the oxidation of 


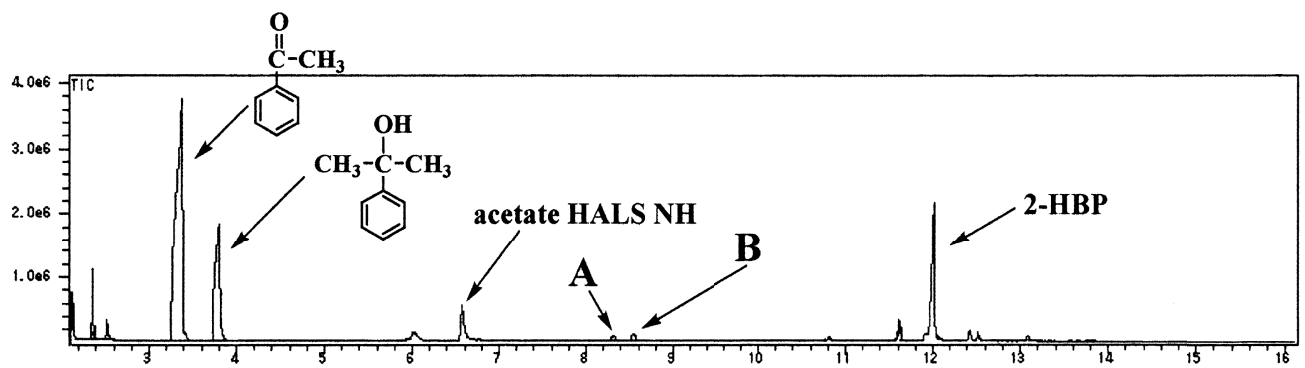

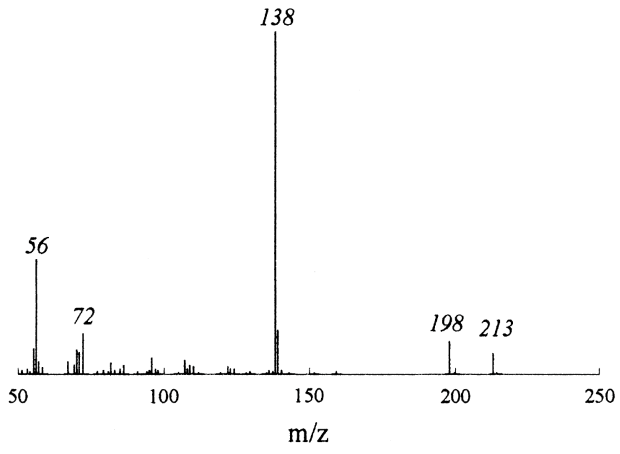

product A

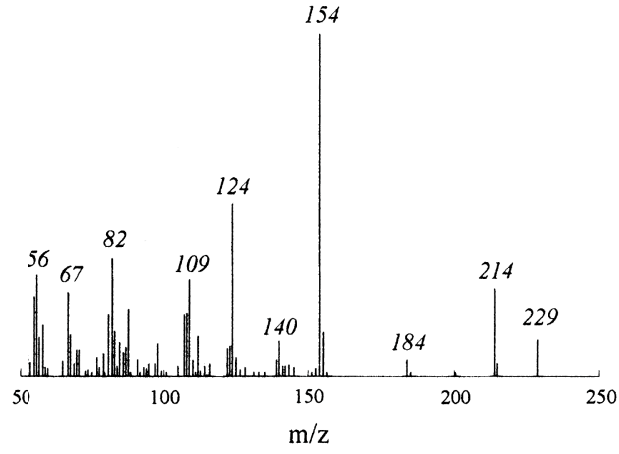

product B

In chlorobenzene under $\mathrm{N}_{2}$ at $120^{\circ} \mathrm{C}$, [acetate HALS NH] $=[2-\mathrm{HBPl}]=10^{-3} \mathrm{~mol} / l,[\mathrm{CHP}]=10^{-2} \mathrm{~mol} / l$.

FIg. 2 Gas Chromatogram of Reaction Products at $20 \mathrm{~h}$

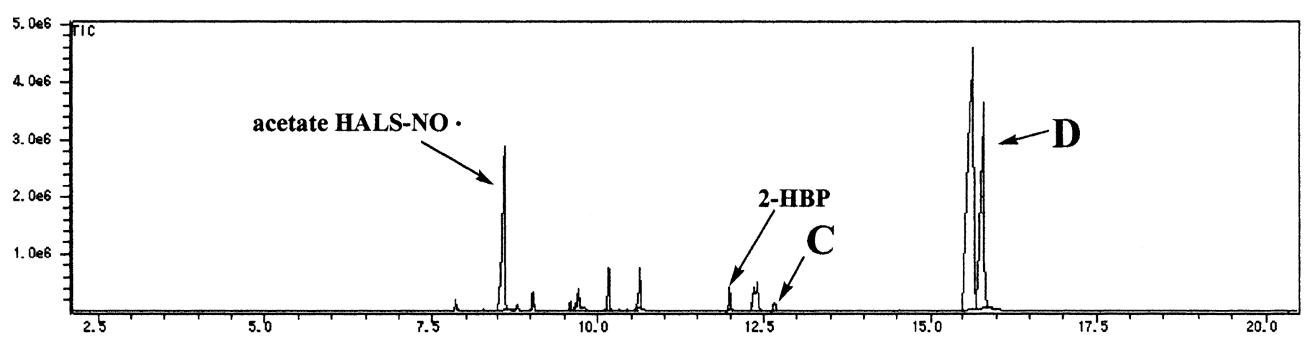

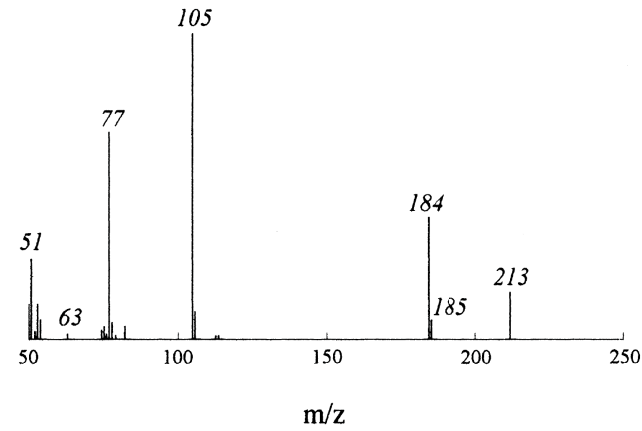

product C

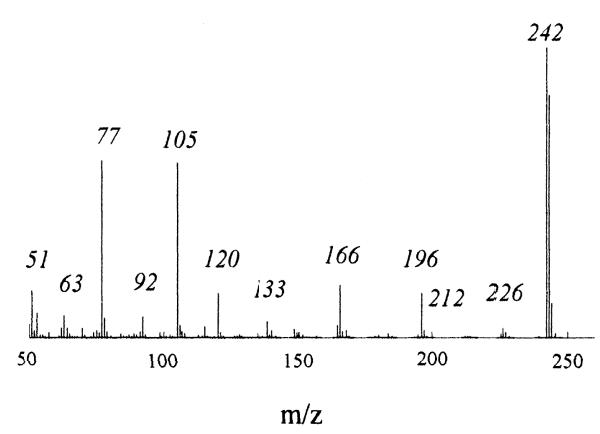

product D

In chlorobenzene under $\mathrm{N}_{2}$ at $120^{\circ} \mathrm{C}$, [acetate $\left.\mathrm{HALS} \mathrm{N}^{+}=\mathrm{O}\right]=[2-\mathrm{HBPl}]=10^{-2} \mathrm{~mol} / \mathrm{l}$.

Fig. 3 Gas Chromatogram of Reaction Products of Acetate HALS $\mathrm{N}^{+}=\mathrm{O}$ and 2-HBP at $15 \mathrm{~min}$ 


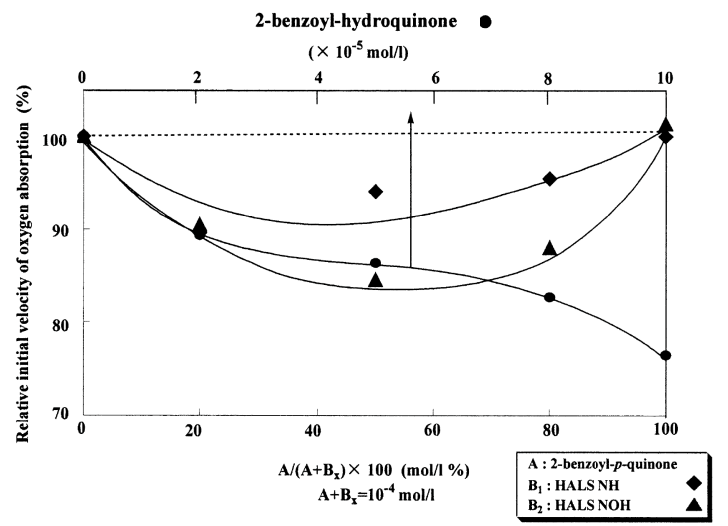

In chlorobenzene at $50^{\circ} \mathrm{C}$, under $\mathrm{O}_{2}$ and UV irradiation; [styrene] = $2.0 \mathrm{M}\left(1 \mathrm{M}=1 \mathrm{~mol} \cdot \mathrm{dm}^{-3}\right),[$ AIBN $]=10^{-2} \mathrm{M}$

Fig. 4 Synergistic Effect between 2-Benzoyl-p-quinone (A) and $\operatorname{HALS}\left(\mathrm{B}_{x}\right)$

Product C<smiles>O=C1C=CC(=O)C(C(=O)c2ccccc2)=C1</smiles>

2-HBP in extremely smaller amount. The BHT donates HALS a proton easily to form HALS nitrosonium, but 2-hydroxybenzophenone is found difficult to donate a proton and very stable against HALS. In other words, UVA do not bring so severe antagonism with HALS as BHT.

\section{4. Synergism in Photo-antioxidation of HALS and UVA}

In the past, the synergism between HALS and phenols under UV light was explained by the regeneration of a phenol by the action of HALS on a quinone formed by the radical catching of a phenol (see Scheme 1) ${ }^{3}$. The quinone absorbs UV rays, and the resulting excited quinoid compound is reduced to a phenol by the action of HALS.

Shown in Fig. 4 is a synergistic interaction of 2-benzoyl- $p$-quinone with HALS in photo-oxidation. A vertical axis shows relative initial velocity of oxygen absorption, and a figure, $100 \%$, means a non-inhibited photo-oxidation. A curve below dotted line shows synergism of two additives, while a curve above the line shows antagonism. Interestingly, both HALS $\mathrm{NOH}$ and HALS NH showed similar synergism with the quinone. Either HALS or quinone alone does not prevent any photo-oxidation, but a combination of both additives shows photo-antioxidant activities. In this case, HALS NOH is found to show a higher synergism than HALS NH. This result coincides completely

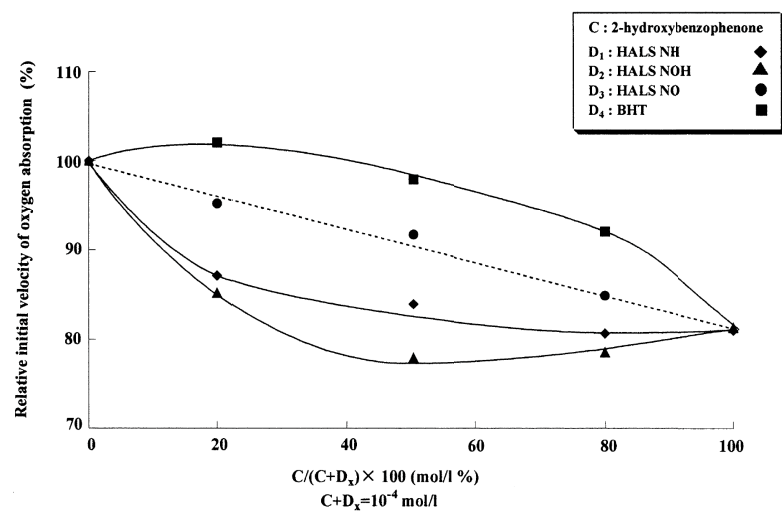

In chlorobenzene at $50^{\circ} \mathrm{C}$, under $\mathrm{O}_{2}$ and UV irradiation; [styrene] $=$ $2.0 \mathrm{M}\left(1 \mathrm{M}=1 \mathrm{~mol} \cdot \mathrm{dm}^{-3}\right),[\mathrm{AIBN}]=10^{-2} \mathrm{M}$.

Fig. 5 Interaction between 2-HBP (C) and Another Additive ( $\left.\mathrm{D}_{x}\right)$

with the result obtained in the synergism between HALS and phenols ${ }^{3)}$. Thus, UVA are regenerated by the action of HALS, even if UVA are eventually converted into a quinone due to the attack of peroxy radicals.

Shown in Fig. 4 also is the actual photo-antioxidant activity of a regenerated UVA, for example 2-benzoylhydroquinone, which is the most plausible UVA regenerated from the quinoid compound. The concentration of 2-benzoyl-p-quinone was made same as that of $\mathrm{A}$ in $\mathrm{A}+\mathrm{B}_{x}$ shown in Fig 4. The similar oxidationsuppressing curves are observed at a less concentration than $5 \times 10^{-5} \mathrm{~mol} / l$ of 2-benzoyl-hydroquinone, on comparing the result of the combination of 2-benzoylp-quinone and HALS NOH with that of 2-benzoyl-hydroquinone. This fact can be fully explained by the mechanism that 2-benzoyl-p-quinone is reduced to 2-benzoyl-hydroquinone by an equivalently excess of HALS under UV irradiation. On the contrary, 2benzoyl-hydroquinone is not produced sufficiently at a less concentration of HALS than that of 2-benzoyl-pquinone. Therefore, a photo-antioxidant activity is decreased over $5 \times 10^{-5} \mathrm{~mol} / l$ of 2-benzoyl-p-quinone.

Shown in Fig. 5 is the interaction of UVA with various radical trapping substrates. Interestingly, 2-HBP is found to show the synergism with HALS NH having little UV-absorbing ability by itself. Furthermore, HALS NOH also shows the almost same synergism as HALS NH. If the synergism is based on the radical catching ability of HALS, HALS NO, having a high radical catching ability, would show higher synergism, compared with that of HALS NH. However, the result shown in Fig. 5 clearly exhibits no interaction between HALS NO and 2-hydroxybenzophenone. In addition, a strong radical-catching substrate, BHT, showed antagonism instead of synergism. Therefore, the above-mentioned synergism is not ascribable to such radical trapping of HALS as proposed by Pickett 


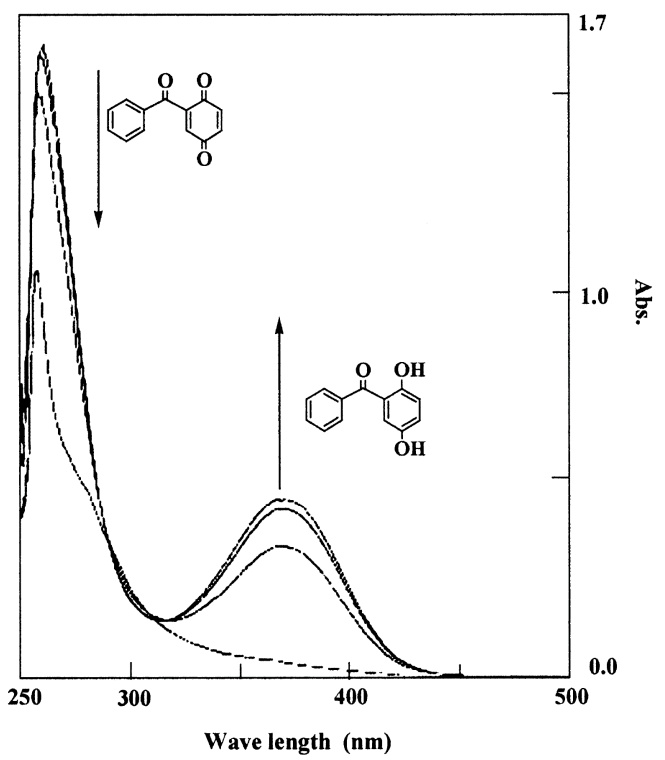

In $\mathrm{CCl}_{4}$ under $\mathrm{N}_{2}$ and diffused light at $50^{\circ} \mathrm{C}$, [quinone] $=$ [HALS $\mathrm{NOH}]=10^{-4} \mathrm{~mol} / l$.

Fig 6 UV Spectra of the Mixture of 2-Benzoyl-p-quinone and HALS NOH with Time

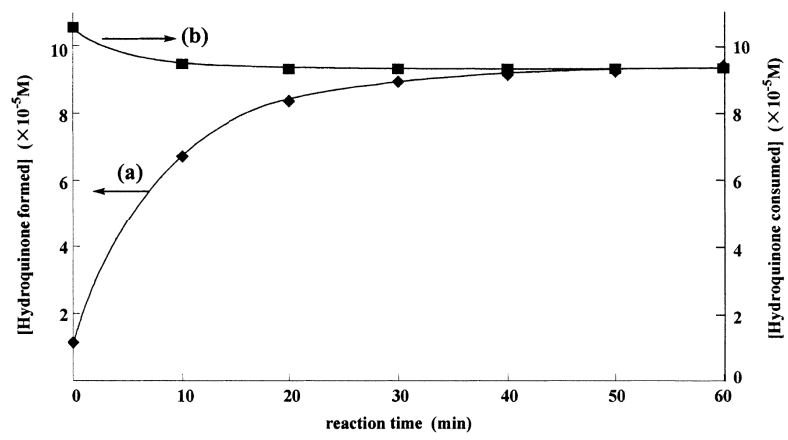

In $\mathrm{CCl}_{4}$ under $\mathrm{N}_{2}$ and diffused light at $50^{\circ} \mathrm{C}$, (a) [quinone] $=$ [HALS $\mathrm{NOH}]=10^{-4} \mathrm{~mol} / l$, (b) [hydroquinone $]=[\mathrm{HALS} \mathrm{NO}]=10^{-4} \mathrm{~mol} / l$.

Fig 7 Relationship between Formation (a) and Consumption (b) of Hydroquinone et al. ${ }^{3)}$.

\section{5. Interaction of HALS Hydroxylamine with Quinone}

In Paragraph 3. 4., UVA show the synergism with either HALS NOH or HALS NH in photo-antioxidation. This phenomenon may be ascribed to the regeneration of a new UVA by the action of HALS, even if UVA are converted into corresponding quinones. Shown in Fig. 6 are UV spectra of the interaction of HALS NOH with 2-benzoyl-p-quinone under diffused light. At first, only one peak of the quinone is observed at $265 \mathrm{~nm}$, but a new peak which is assigned to 2,5-dihydroxybenzophenone appears at $372 \mathrm{~nm}$. The latter peak increases, while the former quinone peak decreases with time. It is confirmed, therefore, that the hydroquinone is formed by the interaction of HALS with a quinone under diffused light. Figure 7 shows both the formation of the hydroquinone from a quinone by the reaction with HALS NOH and the consumption of hydroquinone by the reaction with HALS NO. The formation and consumption amounts of the hydroquinone became constant with the progress of time. This result means the following equilibrium reaction (see Scheme 1):

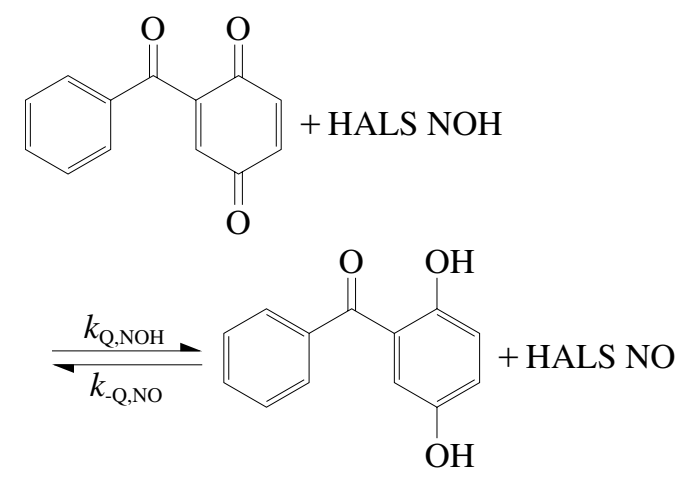

Thus, the equilibrium constant can be calculated.

$K=k_{\mathrm{Q}, \mathrm{NOH}} / k_{\text {-Q,NO }}$

Table 1 shows the rate and equilibrium constants of the reaction concerning 2-hydroxybenzophenone, together with that concerning BHT. 2-Benzoyl-p-

Table 1 Kinetic Parameters in Interaction of a Phenol with HALS at $50^{\circ} \mathrm{C}$

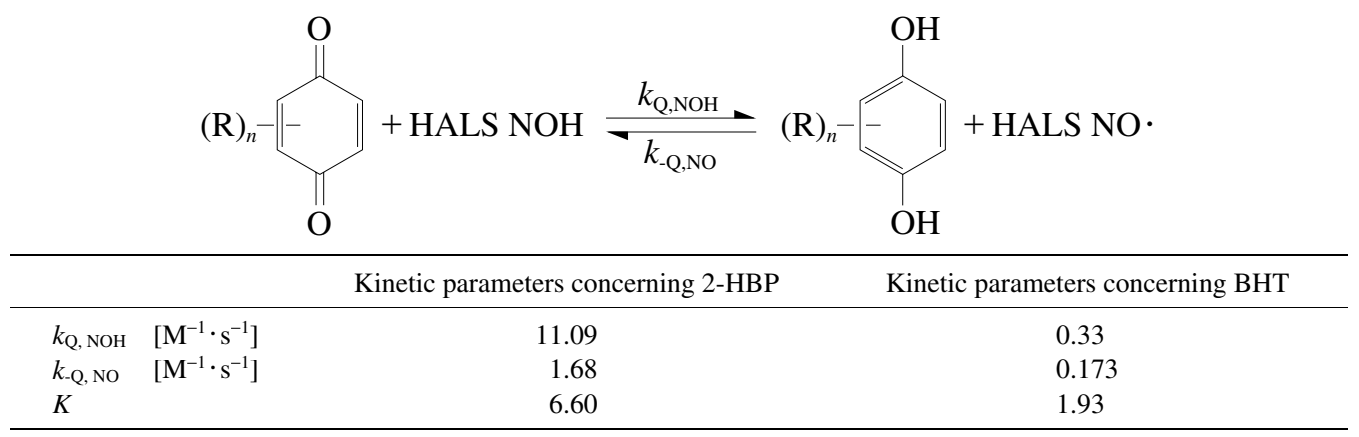


quinone has a much higher rate constant $\left(k_{\mathrm{Q}, \mathrm{NOH}}\right)$, compared with 2,6-di- $t$-butyl- $p$-quinone. That is, the quinone of UVA is more easily reduced to the corresponding hydroquinone, namely a new type of UVA.

On the other hand, the reaction of hydroquinone with HALS nitroxide, namely the reverse reaction seems harder to proceed in the case of UVA. These results shows that 2-benzoyl-hydroquinone is much more stable than 2,6-di-t-butyl-hydroquinone. That is, 2-hydroxybenzophenone can continue to maintain its function of UV absorption over a longer period.

\section{Conclusions}

In general, an ultraviolet absorber, one of phenolic antioxidants, is different from an antioxidant phenol in terms of the interaction with HALS. In this study, the interactions of UVA or phenol with HALS are compared with each other (see Table 2). The UVA do not accelerate the formation of HALS nitrosonium so easily as phenol. Even if a HALS nitrosonium is formed, it can hardly oxidize UVA. On the other hand, if UVA are eventually converted to quinones, they are reduced by HALS promptly to the corresponding hydroquinonetype UVA.

In conclusion, an antioxidant phenol apparently
Table 2 Apparent Interaction of Phenols with HALS

\begin{tabular}{lccl}
\hline & \multicolumn{2}{c}{ Interaction of phenols with HALS } & \multirow{2}{*}{$\begin{array}{c}\text { Apparent } \\
\text { interaction }\end{array}$} \\
\cline { 2 - 3 } & antagonism & synergism & synergism \\
Benzophenone & $\bigcirc$ & $\bigcirc$ & antagonism \\
BHT & $\bigcirc$ & $\triangle$ & \\
\hline
\end{tabular}

(O) strong, $\bigcirc$ medium, $\triangle$ weak.

shows the antagonism with HALS due to higher antagonism than synergism, while UVA shows the synergism in a combination of strong synergism and weak antagonism.

\section{References}

1) Yamashita, H., Ohkatsu, Y., Polym. Deg. Stab., 80, 421 (2003).

2) Yamashita, H., Banno, K., Ohkatsu, Y., J. Appl. Poly. Sci., 102,1310 (2006).

3) Ohkatsu, Y., Yamaguchi, K., Sengoku, T., Sato, T., Sekiyu Gakkaishi (J. Jpn. Petrol. Inst.), 37, (4), 405 (1994).

4) Pickett, J. E., Moore, J. E., Polym. Deg. Stab., 42, 231 (1993).

5) Decker, C., Zahouily, K., Polym. Mater. Sci. Eng., 68, 70 (1993).

6) Mizokawa, S., Ohkatsu, Y., J. Jpn. Petrol. Inst., 50, (1), 1 (2007).

7) Kaupp, G., Schmeyers, J., J. Org. Chem., 60, 5494 (1995).

8) Miyazawa, T., Endo, T., Shiihashi, S., Okawara, M., J. Org. Chem., 50, 1332 (1985).

要旨

\author{
ヒンダードアミン系光安定剤と紫外線吸収剤の相互作用 \\ 竹中 宏行, 溝川 茂雄, 大勝 靖一 \\ 工学院大学工学部応用化学科, 167-8677 東京都新宿区西新宿1-24-2
}

\footnotetext{
フェノール系酸化防止剂がヒンダードアミン系光安定剂 （HALS）と拮抗作用を示すのに, 紫外線吸収剤（UVA）がフェ ノール構造を持っているにもかかわらず，なぜ HALS と見か け上相乗作用を示すのかを議論する。HALS と 2,6-di- $t$-butyl4-hydroxytoluene（BHT）の拮抗作用をもたらす原因物質の HALS ニトロソニウムは, 2-ヒドロキシベンゾフェノン (2-HBP) の場合に生成しにくかった。さらに, HALS ニトロソニウムは たとえ生成しても BHT ほど2-HBP を酸化せず, 2-HBPがより 長くかつより効率よく働き続けることができた。これらの結果 は，2-HBP の HALS との弱い拮抗作用およびBHTと HALS の
}

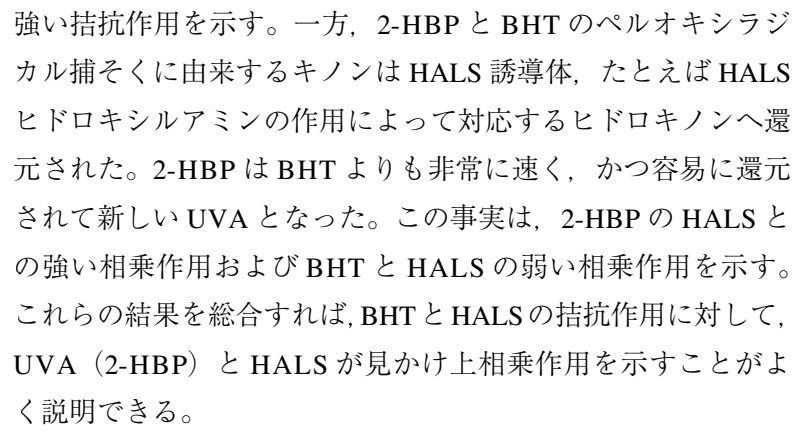

